\title{
Biodegradação de braquetes ortodônticos: avaliação da liberação iônica in vitro
}

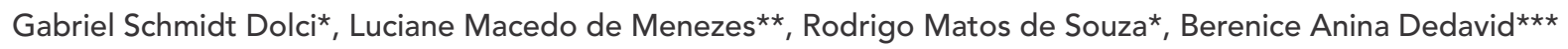

\begin{abstract}
Resumo
Objetivo: avaliar, in vitro, a biodegradação de aparelhos ortodônticos simulados constituídos de braquetes e fios de aço inoxidável. Metodologia: a amostra foi dividida em 2 grupos, de acordo com a marca dos braquetes usados: grupo A - Dyna-Lock, 3M/Unitek (AISI 303); e grupo B - LG Edgewise Standard, American Orthodontics (AISI 316L). Os corpos-de-prova permaneceram incubados em solução salina $(0,05 \%)$ a $36^{\circ} \mathrm{C}$, sob agitação por um período de até 60 dias. A análise da liberação iônica foi realizada por meio de espectrofotometria de absorção atômica. O peso em massa dos braquetes também foi medido antes e após o experimento. Resultados: os resultados indicaram que o grupo A apresentou maior liberação de íns ferro, níquel e cromo do que o grupo B. Além disso, os braquetes do grupo A também mostraram perda de massa, considerada outro indicativo de corrosão. Conclusão: concluiu-se que, nas condições deste experimento, os braquetes do grupo A apresentaram maior biodegradação que os acessórios do grupo B, o que pode estar associado à liga metálica e/ou ao processo de fabricação dos mesmos.
\end{abstract}

Palavras-chave: Corrosão. Braquetes ortodônticos. Fios ortodônticos.

\section{INTRODUÇÃO}

Nos últimos anos, a biocompatibilidade das ligas odontológicas tem sido tópico de inúmeras pesquisas. Entretanto, muitas questões referentes a esse assunto estão longe de ser esclareci$\mathrm{das}^{30}$.

Um dos fatores determinantes da biocompatibilidade das ligas metálicas usadas na Odontologia é a sua resistência à corrosão $0^{9,14,25}$. Os acessórios ortodônticos, no próprio processo de fabricação, ficam expostos a inúmeros fatores físicos e químicos que estimulam sua corrosão. Dentre eles destacam-se: tratamento térmico ${ }^{9}$, soldas ${ }^{2}$ e agentes de polimento ${ }^{12}$. A opção clínica de usar acessórios que apresentem menor biodegradação reduz o risco de danos à saúde do paciente, uma vez que estes tendem a liberar menos íons metálicos para o meio intrabucal.

Maior ênfase tem sido dada à liberação de íons níquel e cromo, uma vez que os efeitos deletérios destes elementos sobre os tecidos humanos já são bem conhecidos ${ }^{4,22,23}$. Pesquisadores têm atribuído ao níquel efeitos carcinogênicos, citotó$\operatorname{xicos}^{4,8,21,22,23}$ e, principalmente, alergênicos ${ }^{19,20}$.

* Mestre em Ortodontia e Ortopedia Facial pela FO - PUCRS.

** Doutora em Ortodontia pela FO - UFRJ. Professora do Curso de Mestrado em Ortodontia da FO - PUCRS.

*** Doutorado em Engenharia de Minas, Metalúrgica e de Materiais (UFRGS). Coordenadora do centro de Microscopia e Microanálise da PUCRS. 
Biodegradação de braquetes ortodônticos: avaliação da liberação iônica in vitro

\begin{tabular}{|c|c|c|c|c|c|c|}
\hline \multirow[b]{2}{*}{ Grupo } & \multicolumn{6}{|c|}{ braquetes } \\
\hline & $\mathbf{n}$ & Marca & Especificação & Tipo de aço & $\begin{array}{c}\text { Composição química } \\
\text { (\% max })\end{array}$ & Observação \\
\hline A & 140 & 3M/ Unitek & $\begin{array}{l}\text { Dynalock, Edgewise } \\
\text { Standard, Slot 0,022" }\end{array}$ & $\mathrm{AISI}^{*} 303$ & $\begin{array}{c}\mathrm{C}=0,15 \% \mathrm{Cr}=17-19 \% \\
\mathrm{Ni}=5,0-10 \% \mathrm{Mn}=2,0 \% \\
\mathrm{Si}=1,0 \% \text { Fe-restante }\end{array}$ & $\begin{array}{l}\text { Ausência de solda } \\
\text { unindo o corpo à base }\end{array}$ \\
\hline B & 140 & $\begin{array}{c}\text { American } \\
\text { Orthodontics }\end{array}$ & $\begin{array}{c}\text { LG Edgewise } \\
\text { Standard, Slot 0,022" }\end{array}$ & $\mathrm{AISI}^{*} 316 \mathrm{~L}$ & $\begin{array}{l}\mathrm{C}=0,030 \% \mathrm{Cr}=16-18 \% \\
\mathrm{Ni}=10-14 \% \mathrm{Mn}=2,0 \% \\
\mathrm{Si}=1,0 \% \mathrm{Fe} \text {-restante }\end{array}$ & $\begin{array}{l}\text { Presença de solda de } \\
\text { prata unindo o corpo à base }\end{array}$ \\
\hline
\end{tabular}

QUADRO 1 - Divisão dos grupos experimentais.

* American Iron Stainlees Steel Institute.

\begin{tabular}{cccc}
\hline Grupo & $\begin{array}{c}\text { Tubos de } \\
\text { ensaio (n)* }\end{array}$ & Fio (n) & Braquetes (n) \\
\hline A & 10 & 20 & 140 \\
B & 10 & 20 & 140 \\
C1 & 4 & $8^{* *}$ & - \\
C2 & $4^{* * *}$ & - & - \\
Total (n) & 28 & 48 & 280 \\
\hline
\end{tabular}

QUADRO 2 - Grupos experimentais (A e B) e Grupos controles (C1 e C2).

* Número de tubos de ensaio contendo $10 \mathrm{ml}$ de solução salina, em cada tempo estudado.

** Os corpos-de-prova do Grupo $\mathrm{C} 1$ eram compostos somente pelo segmento de fio, idêntico ao utilizado nos grupos experimentais, sem braquetes.

*** 0s tubos de ensaio do Grupo C2 continham somente a solução salina.

Visto os inúmeros fatores que influenciam a biodegradação de acessórios ortodônticos e as evidentes conseqüências indesejáveis desse processo, este estudo teve o intuito de investigar, in vitro, os possíveis fenômenos oriundos da corrosão de braquetes metálicos submetidos ao processo de envelhecimento químico-mecânico, dentre eles: a) liberação de íons ferro, níquel e cromo e; b) alterações de peso dos acessórios.

\section{MATERIAL E MÉTODOS}

\section{Avaliação da liberação de íons ferro, níquel e cromo}

Dois diferentes braquetes foram analisados: Dyna-Lock Standard Edgewise (3M Unitek, Monrovia, CA, USA) e LG Edgewise (American Orthodontics, Sheboygan, Wisconsin, USA), os quais foram divididos em 2 grupos experimentais, de acordo com a marca comercial dos acessórios (Quadro 1). Além dos braquetes, foram usados

fios de aço inoxidável $(0,021$ " x 0,025") da marca comercial Rocky Mountain Orthodontics.

Foram analisados 4 grupos (2 experimentais e 2 controles), como pode ser visto no quadro 2 .

Os corpos-de-prova, que simulavam um hemiarco inferior, foram constituídos de braquetes de incisivos $(n=2)$, caninos $(n=1)$ e pré-molares inferiores $(n=2)$. Para os molares $\left(1^{\circ}\right.$ e $\left.2^{\circ}\right)$ foram usados braquetes de incisivos superiores, totalizando 7 acessórios por corpo-de-prova. Os braquetes foram amarrados aos fios com ligadura elástica (GAC Orthodontics, ref. 59-600-14), sendo suas bases cobertas com cera ${ }^{7}$. Este procedimento serviu para evitar a corrosão de tal região e tornar mais fácil a remoção do material da base do braquete, permitindo a pesagem. Cada corpo-deprova foi codificado de forma a identificar os braquetes e fios que compunham o mesmo (Fig. 1).

Para análise da liberação iônica, os corposde-prova foram imersos em tubos de ensaio que continham 10 mililitros de solução salina a 0,05\% (Departamento de Bioquímica da PUCRS). Em cada tubo, foram colocados 2 corpos-de-prova, simulando um arco inferior completo (14 braquetes).

Os grupos A, B, Cl e C2 foram submetidos a um processo de "envelhecimento químico-mecânico". Eles permaneceram sob agitação por 8 horas diárias, com temperatura constante de $36 \pm 1^{\circ} \mathrm{C}$ (Banho Dubnoff, Departamento de Bioquímica da PUCRS), por um período de até 60 dias.

Completado um dia de imersão (T1), os corpos-de-prova foram retirados e inseridos em novos 
tubos de ensaio contendo $10 \mathrm{ml}$ da solução salina. Após 7, 14, 28 e 60 dias, correspondendo a T2, $\mathrm{T} 3$, T4 e T5, respectivamente, tal procedimento foi repetido. A cada troca, os tubos contendo a solução antiga eram identificados e armazenados em refrigerador. Para evitar a proliferação de microrganismos, foram adicionadas às soluções 6 gotas de ácido nítrico na concentração de 0,5 Molar $\left(\mathrm{HNO}_{3} 0,5 \mathrm{M}\right)$, conforme descrito por Sória ${ }^{27}$.

Após, as soluções foram analisadas por meio de um espectrofotômetro eletrotérmico de absorção atômica com forno de grafite (Analyst 800 Perkin Elmer, USA), onde foram quantificados os íons ferro, níquel e cromo.

\section{Pesagem dos braquetes}

A pesagem dos braquetes foi realizada por meio de uma microbalança (Metter Toledo, AG204, Suíça) com precisão de $0,1 \mathrm{mg}$. Setenta braquetes de cada grupo foram pesados individualmente antes (T0) e depois de permanecerem 60 dias imersos em solução salina (T5).

Previamente à pesagem, em T5, realizou-se a remoção dos produtos de corrosão da superfície dos acessórios, por meio da secagem dos acessórios com jato de nitrogênio e limpeza mecânica com pincel.

\section{Tratamento estatístico}

Para verificação da normalidade dos dados foi utilizado o teste não-paramétrico KolmogorovSmirnov. Este teste é considerado uma prova de aderência, diz respeito ao grau de concordância

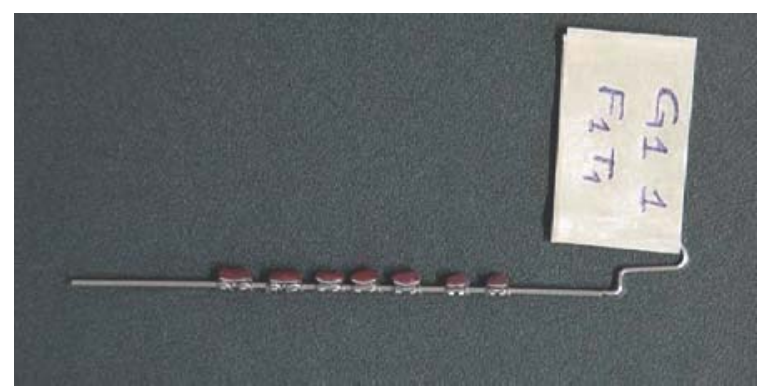

FIGURA 1 - Corpo-de-prova pronto para ser imerso em solução salina. entre a distribuição de um conjunto de valores amostrais e determinada distribuição teórica específica, neste caso, a distribuição normal. Para os dados obtidos neste estudo, esta condição da normalidade não foi garantida para algumas variáveis, por isso foram utilizados testes não-paramétricos (Friedman, Mann-Whitney e Kruskal-Wallis). Para o processamento dos dados, foi utilizado o software SPSS versão 10.0.

\section{RESULTADOS}

\section{Avaliação da liberação de íons ferro, níquel, e cromo}

Os resultados da avaliação da liberação de íons ferro, níquel e cromo estão expressos nas tabelas 1 a 7 .

Observou-se uma relação positiva entre tempo e liberação iônica, ou seja, as concentrações de íons ferro, níquel e cromo liberados em solução salina aumentaram significativamente em função do tempo $(\mathrm{p}<0,01)$, especialmente no grupo A (Tab. $1,2)$. Também verificou -se que o íon ferro foi o mais liberado em todos tempos estudados ( $\mathrm{Tl}$ a T5), nos grupos A e B (Tab. 3, 4).

Houve diferença na liberação de íons ferro, níquel e cromo entre os grupos estudados. O grupo A apresentou maior liberação de íons, seguido pelo grupo $\mathrm{B}(\mathrm{p}<0,01)$, conforme as tabelas 5, 6 e 7 .

\section{Pesagem dos braquetes}

A comparação do peso dos braquetes intragrupos, em T0 e T5, indicou uma redução da massa para os acessórios do grupo A e manutenção do peso dos acessórios do grupo B, conforme demonstra a tabela 8 .

\section{DISCUSSÃO}

\section{Avaliação da liberação de íons ferro, níquel e cromo}

Neste estudo, o tempo foi um dos fatores determinantes sobre a biodegradação dos acessórios ortodônticos (Tab. 1, 2). No grupo A, observouse um aumento significativo da liberação de íons 
ferro, níquel e cromo, em função do tempo, até o final do estudo, confirmando os resultados de outros autores ${ }^{10,11,24,28}$. Já o grupo B apresentou um aumento da liberação de íons ferro, níquel e cromo até o final da $1^{\text {a }}$ semana. Após isso, houve estabilização da liberação iônica, exceto para o íon cromo, que diminuiu sua liberação na $8^{\text {a }}$ semana, o que vai de acordo com estudos de Hwang, Shin e Cha ${ }^{13}$.

Outros pesquisadores demonstraram que a liberação iônica de aparelhos ortodônticos tende a ocorrer, principalmente, nos períodos iniciais, após a inserção destes em boca ou em solução salina ${ }^{1,29}$. De acordo com Eliades et al. ${ }^{6}$, Eliades e Athanasiou $^{7}$, esses resultados podem induzir a falsas conclusões, pois em estudos realizados in vitro, onde a solução não é trocada periodicamente, ocorre a

Tabela 1 - Comparação da liberação de íons ferro, níquel e cromo $(\mu \mathrm{g} / \mathrm{l})$, em função do tempo para os acessórios do grupo A (3M/ Unitek). Análise realizada pelo teste não-paramétrico de Friedman.

\begin{tabular}{|c|c|c|c|c|c|c|}
\hline \multirow{3}{*}{ Tempo } & \multicolumn{6}{|c|}{ íon } \\
\hline & \multicolumn{2}{|c|}{$\mathrm{Fe}$} & \multicolumn{2}{|c|}{$\mathrm{Ni}$} & \multicolumn{2}{|c|}{$\mathrm{Cr}$} \\
\hline & média & d.p. & média & d.p. & média & d.p. \\
\hline T1 & $1,52^{\mathrm{a}}$ & 0,73 & $0,24^{\mathrm{a}}$ & 0,11 & $0,24^{\mathrm{a}}$ & 0,16 \\
\hline T2 & $5,41^{\mathrm{b}}$ & 2,18 & $1,08^{b}$ & 0,47 & $1,48^{b}$ & 0,85 \\
\hline T3 & $12,05^{c}$ & 1,93 & $1,99^{c}$ & 0,28 & $4,80^{c}$ & 0,84 \\
\hline T4 & $11,2^{c}$ & 3,34 & $3,13^{d}$ & 0,49 & $10,2^{d}$ & 4,24 \\
\hline T5 & $80,00^{d}$ & 17,12 & $6,38^{e}$ & 0,71 & $16,19^{\mathrm{e}}$ & 5,38 \\
\hline$p<0,05$ & $*$ & & * & & * & \\
\hline
\end{tabular}

saturação da mesma, o que daria a impressão de uma maior liberação nos períodos iniciais e uma diminuição nos períodos subseqüentes. Já para Barret, Bishara e Quinnn ${ }^{1}$, a redução da liberação de íons níquel, após a $1^{\text {a }}$ semana de inserção de aparelhos fixos simulados em solução salina, pode ser atribuída a dois prováveis fatores: (1) o níquel presente na superfície do aço sofreria corrosão rapidamente durante os primeiros 7 dias e (2) após este período formar-se-iam produtos de corrosão sobre a superfície do aço, dificultando a liberação de íons níquel nos períodos subseqüentes.

Segundo Berge, Gjerdet e Erichsen², a resistência à corrosão de aços inoxidáveis é reduzida em decorrência do processo de soldagem, o que poderia sugerir que os braquetes do grupo B teriam

Tabela 2 - Comparação da liberação de íons ferro, níquel e cromo $(\mu \mathrm{g} / \mathrm{l})$, em função do tempo para os acessórios do grupo B (American Orthodontics). Análise realizada pelo teste não-paramétrico de Friedman.

\begin{tabular}{ccccccc}
\hline & \multicolumn{5}{c}{ íon } \\
\cline { 2 - 7 } Tempo & \multicolumn{2}{c}{ Fe } & \multicolumn{2}{c}{ Ni } & \multicolumn{2}{c}{ Cr } \\
\cline { 2 - 7 } & média & d.p. & média & d.p. & média & d.p. \\
\hline T1 & $0,42^{\mathrm{a}}$ & 0,16 & $0,07^{\mathrm{a}}$ & 0,02 & $0,05^{\mathrm{a}}$ & 0,03 \\
T2 & $0,71^{\mathrm{ab}}$ & 0,56 & $0,14^{\mathrm{b}}$ & 0,08 & $0,08^{\mathrm{a}}$ & 0,07 \\
T3 & $1,02^{\mathrm{b}}$ & 0,49 & $0,16^{\mathrm{b}}$ & 0,06 & $0,17^{\mathrm{b}}$ & 0,09 \\
T4 & $1,32^{\mathrm{b}}$ & 0,84 & $0,20^{\mathrm{b}}$ & 0,09 & $0,25^{\mathrm{c}}$ & 0,14 \\
T5 & $1,28^{\mathrm{b}}$ & 1,16 & $0,23^{\mathrm{b}}$ & 0,15 & $0,12^{\mathrm{ab}}$ & 0,09 \\
\hline $\mathbf{p}<\mathbf{0 , 0 5}$ & $*$ & & $*$ & & $*$ & \\
\hline
\end{tabular}

* Médias com as mesmas letras não diferem entre si.

Tabela 3 - Comparação da liberação de íons ferro, níquel e cromo $(\mu \mathrm{g} / \mathrm{l})$, em cada tempo estudado, para os acessórios do grupo A (3M/ Unitek). Análise realizada pelo teste não-paramétrico de Kruskal-Wallis.

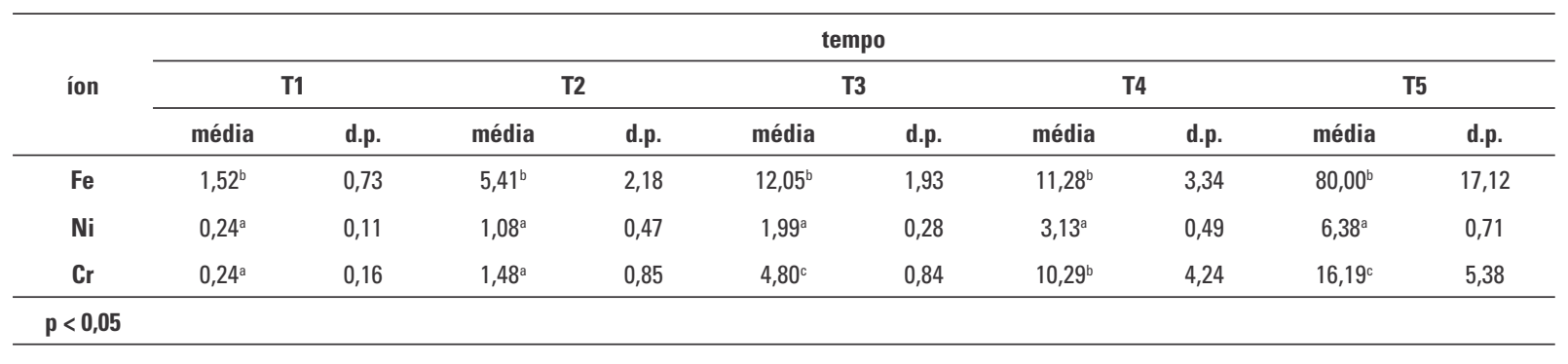

* Médias com as mesmas letras não diferem entre si. 
Tabela 4 - Comparação da liberação de íons ferro, níquel e cromo $(\mu \mathrm{g} / \mathrm{l})$, em cada tempo estudado, para os acessórios do grupo B (American Orthodontics). Análise realizada pelo teste não-paramétrico de Kruskal-Wallis

\begin{tabular}{|c|c|c|c|c|c|c|c|c|c|c|}
\hline \multirow{3}{*}{ íon } & \multicolumn{10}{|c|}{ tempo } \\
\hline & \multicolumn{2}{|c|}{ T1 } & \multicolumn{2}{|c|}{ T2 } & \multicolumn{2}{|c|}{ T3 } & \multicolumn{2}{|c|}{ T4 } & \multicolumn{2}{|c|}{ T5 } \\
\hline & média & d.p. & média & d.p. & média & d.p. & média & d.p. & média & d.p. \\
\hline $\mathrm{Fe}$ & $0,42^{\mathrm{b}}$ & 0,16 & $0,71^{\mathrm{b}}$ & 0,56 & $1,02^{b}$ & 0,49 & $1,32^{b}$ & 0,84 & $1,28^{b}$ & 1,16 \\
\hline $\mathrm{Ni}$ & $0,07^{\mathrm{a}}$ & 0,02 & $0,14^{\mathrm{a}}$ & 0,08 & $0,16^{\mathrm{a}}$ & 0,06 & $0,20^{\mathrm{a}}$ & 0,09 & $0,23^{\mathrm{a}}$ & 0,15 \\
\hline $\mathrm{Cr}$ & $0,05^{\mathrm{a}}$ & 0,03 & $0,08^{\mathrm{a}}$ & 0,07 & $0,17^{\mathrm{a}}$ & 0,09 & $0,25^{\mathrm{a}}$ & 0,14 & $0,12^{c}$ & 0,09 \\
\hline$p<0,05$ & * & & * & & * & & * & & * & \\
\hline
\end{tabular}

* Médias com as mesmas letras não diferem entre si.

Tabela 5 - Comparação entre as médias de íons ferro ( $\mu \mathrm{g} / \mathrm{l})$ liberados pelos diferentes grupos, nos diferentes tempos estudados. Análise realizada pelo teste não-paramétrico de Kruskall-Wallis.

\begin{tabular}{|c|c|c|c|c|c|c|c|}
\hline \multirow{2}{*}{ grupo } & \multicolumn{6}{|c|}{ tempo } & \multirow{2}{*}{ total } \\
\hline & & T1 (1 d) & T2 (7 d) & T3 (14 d) & T4 (28 d) & T5 (60 d) & \\
\hline \multirow{2}{*}{$A\left(n^{* *}=10\right)$} & média & $1,52^{\mathrm{a}}$ & $5,41^{a}$ & $12,05^{\mathrm{a}}$ & $11,28^{a}$ & $80,00^{\mathrm{a}}$ & \multirow{2}{*}{$110,26^{a}$} \\
\hline & d.p. & 0,73 & 2,18 & 1,93 & 3,34 & 17,12 & \\
\hline \multirow{2}{*}{$B\left(n^{* *}=10\right)$} & média & $0,42^{\mathrm{b}}$ & $0,71^{\mathrm{b}}$ & $1,02^{b}$ & $1,32^{b}$ & $1,28^{b}$ & \multirow{2}{*}{$4,75^{b}$} \\
\hline & d.p. & 0,16 & 0,56 & 0,49 & 0,84 & 1,16 & \\
\hline \multirow{2}{*}{ C1 $\left(n^{* *}=4\right)$} & média & $0,16^{c}$ & $0,08^{c}$ & $0,10^{c}$ & $0,11^{c}$ & $0,15^{c}$ & \multirow{2}{*}{$0,60^{c}$} \\
\hline & d.p. & 0,06 & 0,02 & 0,03 & 0,06 & 0,06 & \\
\hline \multirow{2}{*}{ C2 $\left(n^{* *}=4\right)$} & média & $0,12^{c}$ & $0,13^{c}$ & $0,12^{c}$ & $0,11^{c}$ & $0,12^{c}$ & \multirow{2}{*}{$0,60^{c}$} \\
\hline & d.p. & 0,05 & 0,05 & 0,06 & 0,03 & 0,06 & \\
\hline$p<0,05$ & & * & * & * & * & * & * \\
\hline
\end{tabular}

* Médias com as mesmas letras não diferem entre si.

** número de tubos de ensaio, nos quais foi realizada a coleta de solução salina.

Tabela 6 - Comparação entre as médias de íons níquel ( $\mu \mathrm{g} / \mathrm{l})$ liberados pelos diferentes grupos, nos diferentes tempos estudados. Análise realizada pelo teste não-paramétrico de Kruskall-Wallis.

\begin{tabular}{|c|c|c|c|c|c|c|c|}
\hline \multirow{2}{*}{ grupo } & & \multicolumn{5}{|c|}{ tempo } & \multirow{2}{*}{ total } \\
\hline & & $\mathrm{T} 1$ (1 d) & T2 (7 d) & T3 (14 d) & T4 (28 d) & T5 (60 d) & \\
\hline \multirow{2}{*}{$A\left(n^{* *}=10\right)$} & média & $0,24^{\mathrm{a}}$ & $1,08^{\mathrm{a}}$ & $1,99^{a}$ & $3,13^{\mathrm{a}}$ & $6,38^{a}$ & \multirow{2}{*}{$12,82^{\circ}$} \\
\hline & d.p. & 0,11 & 0,47 & 0,28 & 0,49 & 0,71 & \\
\hline \multirow{2}{*}{$B\left(n^{* *}=10\right)$} & média & $0,07^{\mathrm{b}}$ & $0,14^{b}$ & $0,16^{b}$ & $0,20^{\mathrm{b}}$ & $0,23^{b}$ & \multirow{2}{*}{$0,80^{b}$} \\
\hline & d.p. & 0,02 & 0,08 & 0,06 & 0,09 & 0,15 & \\
\hline \multirow{2}{*}{$C 1\left(n^{* *}=10\right)$} & média & $0,04^{b}$ & $0,06^{b c}$ & $0,06^{c}$ & $0,05^{c}$ & $0,07^{c}$ & \multirow{2}{*}{$0,28^{c}$} \\
\hline & d.p. & 0,04 & 0,01 & 0,02 & 0,02 & 0,02 & \\
\hline \multirow{2}{*}{$C 2\left(n^{* *}=10\right)$} & média & $0,08^{b}$ & $0,05^{c}$ & $0,04^{c}$ & $0,07^{c}$ & $0,07^{c}$ & \multirow{2}{*}{$0,31^{\mathrm{c}}$} \\
\hline & d.p. & 0,01 & 0,01 & 0,02 & 0,01 & 0,01 & \\
\hline$p<0,05$ & & * & * & * & * & * & * \\
\hline
\end{tabular}

* Médias com as mesmas letras não diferem entre si.

** Número de tubos de ensaio, nos quais foi realizada a coleta de solução salina. 
Tabela 7 - Comparação entre as médias de íons cromo ( $\mu \mathrm{g} / \mathrm{ll}$ liberados pelos diferentes grupos, nos diferentes tempos estudados. Análise realizada pelo teste não-paramétrico de Kruskall-Wallis.

\begin{tabular}{|c|c|c|c|c|c|c|c|}
\hline \multirow{2}{*}{ grupo } & \multicolumn{6}{|c|}{ tempo } & \multirow{2}{*}{ total } \\
\hline & & $\mathrm{T} 1$ (1 d) & T2 (7 d) & $\mathrm{T} 3$ (14 d) & T4 (28 d) & $\mathrm{T} 5(60 \mathrm{~d})$ & \\
\hline \multirow{2}{*}{$A\left(n^{* *}=10\right)$} & média & $0,24^{\mathrm{a}}$ & $1,48^{\mathrm{a}}$ & $4,80^{\mathrm{a}}$ & $10,29^{a}$ & $16,19^{a}$ & \multirow{2}{*}{$33,1^{\circ}$} \\
\hline & d.p. & 0,16 & 0,85 & 0,84 & 4,24 & 5,38 & \\
\hline \multirow{2}{*}{$B\left(n^{* *}=10\right)$} & média & $0,05^{b}$ & $0,08^{b}$ & $0,17^{\mathrm{b}}$ & $0,25^{b}$ & $0,12^{b}$ & \multirow{2}{*}{$0,67^{b}$} \\
\hline & d.p. & 0,03 & 0,07 & 0,09 & 0,14 & 0,09 & \\
\hline \multirow{2}{*}{ C1 $\left(n^{* *}=10\right)$} & média & $0,03^{c}$ & $0,03^{c}$ & $0,02^{c}$ & $0,02^{c}$ & $0,04^{c}$ & \multirow{2}{*}{$0,14^{\mathrm{c}}$} \\
\hline & d.p. & 0,01 & 0,02 & 0,01 & 0,01 & 0,02 & \\
\hline \multirow{2}{*}{$C 2\left(n^{* *}=10\right)$} & média & $0,00^{d}$ & $0,00^{d}$ & $0,00^{d}$ & $0,00^{d}$ & $0,00^{d}$ & \multirow{2}{*}{$0,00^{\mathrm{d}}$} \\
\hline & d.p. & 0 & 0 & 0 & 0 & 0 & \\
\hline$p<0,05$ & & * & * & * & * & * & * \\
\hline
\end{tabular}

* Médias com as mesmas letras não diferem entre si.

** Número de tubos de ensaio, nos quais foi realizada a coleta de solução salina.

Tabela 8 - Comparação das médias de peso (em gramas) dos braquetes antes (TO) e depois de terem permanecido 60 dias imersos em solução salina (T5). Análise realizada pelo teste não-paramétrico de Wilcoxon.

\begin{tabular}{ccccc}
\hline \multirow{2}{*}{ tempo } & \multicolumn{3}{c}{ grupo } \\
\cline { 2 - 5 } & \multicolumn{2}{c}{$\mathbf{A}(\mathbf{n}=\mathbf{7 0})$} & \multicolumn{2}{c}{$\mathbf{B}(\mathbf{n}=\mathbf{7 0})$} \\
\cline { 2 - 5 } & média & d.p. & média & d.p. \\
\hline T0 & $0,065^{\mathrm{a}}$ & 0,08 & $0,060^{\mathrm{a}}$ & 0,06 \\
T5 & $0,063^{\mathrm{b}}$ & 0,07 & $0,059^{\mathrm{a}}$ & 0,09 \\
\hline $\mathbf{p}<\mathbf{0 , 0 5}$ & $*$ & & n.s. \\
\hline
\end{tabular}

* Médias com as mesmas letras não diferem entre si.

maior liberação de íons. Isso ocorreria porque, durante o processo de soldagem, o metal é submetido a elevadas temperaturas, o que aumentaria sua suscetibilidade à corrosão ${ }^{15}$. Porém, vale lembrar que os acessórios avaliados nesta pesquisa apresentavam composições diferentes (AISI 303 grupo A e AISI 316L grupo B), podendo ter sido fator decisivo na diferença na liberação iônica entre os grupos experimentais. Diversos estudos ${ }^{5,16,17,27}$ têm relatado a maior resistência à corrosão dos aços AISI 316L, confirmando os achados deste estudo.

Nesta pesquisa, a liberação diária de íons níquel e cromo foi estimada tomando-se os valores totais de liberação dos íons (equivalente a 14 braquetes), multiplicando-os por 2 (28 braquetes, correspon- dente a um aparelho ortodôntico completo), sendo o resultado dividido pelo número de dias. Desta forma, os valores diários de liberação dos íons níquel e cromo seriam de $0,43 \mu$ g e $1,10 \mu$ g no grupo $\mathrm{A}$, e $0,03 \mu \mathrm{g}$ e $0,02 \mu \mathrm{g}$ no grupo $B$, valores que estão bem abaixo da quantidade ingerida diariamente, 500 $\mathrm{gg}$ e $100 \mu g$, respectivamente ${ }^{26}$. Contudo, a liberação iônica observada neste estudo não deve ser considerada desprezível ou clinicamente insignificante, uma vez que estudos têm relatado que o tempo de tratamento ortodôntico associado à composição das ligas usadas em Ortodontia é capaz de causar injúrias aos tecidos moles intrabucais ${ }^{3,8}$.

\section{Pesagem dos braquetes}

$\mathrm{Na}$ Ortodontia, poucos estudos se preocupam em estudar alterações de peso de acessórios submetidos a meios oxidantes ${ }^{27,29}$, apesar de ser este o método mais antigo para avaliar a corrosão. Os resultados desta pesquisa indicaram que os braquetes do grupo $\mathrm{A}$ (AISI 303) apresentaram perda significativa de peso

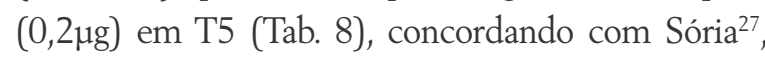
que observou uma redução de peso $(0,3 \mu \mathrm{g})$ em braquetes confeccionados com aço AISI 303, após esses terem permanecido 60 dias imersos em solução salina a $0,05 \%$. Segundo Matasa ${ }^{18}$, a perda de peso é um indicativo de corrosão uniforme. 


\section{CONCLUSÕES}

Após a análise por espectrofotometria de absorção atômica e pesagem dos braquetes pôde-se concluir que:

1) A biodegradação de acessórios ortodônticos em solução salina, independente do processo de fabricação ou liga metálica constituinte, ocorreu principalmente pela liberação de íons ferro.

2) Os braquetes do grupo A (peça única, AISI 303) apresentaram maior liberação de íons ferro, níquel e cromo do que os acessórios do grupo B (peças combinadas, AISI 316L), em todos os tempos estudados.

3) No grupo $A$, a liberação iônica aumentou em função do tempo $(\mathrm{T} 1<\mathrm{T} 2<\mathrm{T} 3<\mathrm{T} 4<\mathrm{T} 5)$. Já no grupo B houve uma tendência de estabilização da liberação de íons, após 7 dias (T2).

4) Os braquetes do grupo A apresentaram significativa perda de massa em $\mathrm{T} 5$.

\title{
Biodegradation of orthodontic brackets: in vitro ion release
}

\begin{abstract}
Objective: The purpose of this study was to evaluate, in vitro, the biodegradation of simulated orthodontic appliances consisting of stainless steel brackets and wires. Materials and methodos: The sample was divided in 2 groups, according to brackets brand: group A - Dyna-Lock, 3M/ Unitek (AISI 303); and group B - LG Edgewise Standard, American Orthodontics (AISI 316L). The specimens (simulated orthodontic appliances) were incubated in saline solution $(0.05 \%)$, in shake, at $36^{\circ} \mathrm{C}$, for 60 days. The ion release was detected by atomic absorption spectrophotometer. The weight of brackets was also measured before and after the test. Results: The results indicated that group A released more ions iron, nickel and chromium than group B. Moreover, the brackets in group A also presented weight loss, which is considered an indicator of corrosion. Conclusion: It was concluded that, under the present study conditions, the brackets from group A presented a higher biodegradation than group's B brackets, what could be associated to composition and manufacturing process of these brackets.
\end{abstract}

Key words: Corrosion. Orthodontic brackets. Orthodontic wires.

\section{REFERÊNCIAS}

1. BARRET, R. D.; BISHARA, S. E.; QUINN, J. K. Biodegradation of orthodontic appliances. Part I. Biodegradation of nickel and chromium in vitro. Am. J. Orthod. Dentofacial Orthop., St. Louis, v. 103, no. 1, p. 8-14, Jan. 1993.

2. BERGE, M.; GJERDET, N. R.; ERICHSEN, E. S. Corrosion of silver soldered orthodontic wires. Acta Odontol. Scand., Oslo, v. 40, no. 2, p. 75-79, 1982.

3. BISHARA, S. E. Oral lesion caused by an orthodontic retainer: a case report. Am. J. Orthod. Dentofacial Orthop., St. Louis, v. 108 , no. 2, p. 115-117, Aug. 1995.
4. BOUR, H. et al. Establishment of nickel-specific T Cell lines from patients with allergic contact dermatitis: comparison of different protocols. Clin. Immunol. Immunopathol., Orlando, v. 73 , no. 1, p. 142-145, Oct. 1994.

5. CEEN, R. F.; GWINNETT, A. J. Indelible iatrogenic staining of enamel following debonding. J. Clin. Orthod., Boulder, v. 14 , no. 10, p. 713-715, Oct. 1980.

6. ELIADES, T. et al. Nickel content of as-received, retrieved and recycled stainless steel brackets. Am. J. Orthod. Dentofacial Orthop., St. Louis, v. 119, no. 3, p. 300-336, Mar. 2002. 
7. ELIADES, T.; ATHANASIOU, A. In vivo aging of orthodontic alloys: implications for corrosion potential, nickel release, and biocompatibility. Angle Orthod., Appleton, v. 72, no. 3, p. 222-237, June 2002.

8. FACCIONI, F. et al. In vivo study on metal release from fixed orthodontic appliances and DNA damage in oral mucosa.

Am. J. Orthod. Dentofacial Orthop., St. Louis, v. 124, no. 6, p. 687-694, Dec. 1994.

9. GJERDET, N. R.; HERO, H. Metal release from heat-treated orthodontic archwires. Acta Odontol. Scand., Oslo, v. 45, no. 6 p. 409-414, Dec. 1987.

10. GRIMSDOTTIR, M. R.; GJERDET, N. R.; HENSTEN-PETTERSEN, $H$. A. Composition and in vitro corrosion of orthodontic appliances. Am. J. Orthod. Dentofacial Orthop., St. Louis, v. 101, no. 6, p. 525-32, June 1992.

11. HUANG, T. H.; YEN, C. C.; KAO, C. T. Comparison of ion release from new and recycled orthodontic brackets. Am. J. Orthod. Dentofacial Orthop., St. Louis, v. 120 , no. 1, p. 68-75, July 2001.

12. HUNT, N. P. et al. An investigation into the effects of polishing on surface hardness and corrosion of orthodontic arch wires. Angle Orthod., Appleton, v. 69, no. 5, p. 433-440, 1999.

13. HWANG, C. J.; SHIN, J. W.; CHA, J. Y. Metal release from simulated fixed orthodontic appliances. Am. J. Orthod. Dentofacial Orthop., St. Louis, v. 120, no. 4, p. 383-391, Oct. 2001.

14. JONES, T. K. et al. Dental implications of nickel hypersensitivity. J. Prosthet. Dent., St. Louis, v. 56, no. 4, p. 507-509, Oct. 1986.

15. KOHL, R. W. Metallurgy in Orthodontics. Am. J. Orthod. Dentofacial Orthop., St. Louis, v. 34, no. 1, p. 37-52, Jan 1964.

16. MAIJER, R. I.; SMITH, D. C. Biodegradation of the orthodontic bracket system. Am. J. Orthod. Dentofacial Orthop., St. Louis, v. 90, no. 3, p. 195-198, Sept. 1986.

17. MAIJER, R. I.; SMITH, D. C. Corrosion of orthodontic bracket bases. Am. J. Orthod. Dentofacial Orthop., St. Louis, v. 81 no. 1, p. 43-48, Jan. 1982.

18. MATASA, C. G. Metallography and you II: surface analysis. Orthodontic Materials Insider, Hollywood, v. 11, no. 4, p. 1-7, Dec. 1998
19. MENEZES, L. M: CAMPOS, L. C : OUINTÃO C C BOLOGNESE, A. M. Hypersensitivity to metals in Orthodontics. Am. J. Orthod. Dentofacial Orthop., St. Louis, v. 126, no. 1, p. 58-64, July 2004

20. MENNÉ, T. et al. Patch test reactivity to nickel alloys. Contact. Derm., Copenhagen, v. 16, no. 5, p. 255-259, May 1987.

21. MORAES, $\mathrm{S}$. et al. In vitro osteoblastic differentiation of human bone marrow cells in the presence of metal ions. J. Biomed. Mater. Res. Hoboken, v. 44, no. 2, p. 176-190, Feb. 1999.

22. NIKI, Y. et al. Metal ions induce bone-resorbing cytokine production through the redox pathway in synoviocytes and bone marrow macrophages. Biomaterials, Guilford, v. 24 no. 8, p. 1447-1457, Apr. 2003

23. NOVELLI, E. L. B. et al. Differential/combined effect of water contamination with cadmium and nickel on tissues of rats. Environ. Pollut., Barking, v. 103, no. 2/3, p. 295-300, Nov. 1998.

24. PARK, H. Y.; SHEARER, T. R. In vitro release of nickel and chromium from simulated orthodontic appliances. Am. J. Orthod. Dentofacial Orthop., St. Louis, v. 84, no. 2, p. 156-159, Aug. 1983.

25. SCHMALZ, G.; GARHAMMER, P. Biological interactions of dental cast alloys with oral tissues. Dental Mater., Kidlington, v. 18, no. 5, p. 396-406, July 2002

26. SCHROEDER, H. A.; BALASSA, J. J.; TIPTON, I. H. Abnormal trace metals in man: nickel. J. Chronic. Dis., St. Louis, v. 15, p. 51-65, Jan. 1962

27. SÓRIA, M. L. Avaliação da corrosão de braquetes metálicos 2003. Dissertação (Mestrado em Ortodontia)-Faculdade de Odontologia, PUCRS, Porto Alegre, 2003.

28. SÓRIA, M. L. et al. Avaliação in vitro da liberação de níquel por braquetes metálicos. Rev. Dental Press Ortodon. Ortop. Facial, Maringá, v. 10, n. 3, p. 87-96, maio/jun. 2005.

29. TOMS, A. P. The corrosion of orthodontic wire. Eur. J. Orthod. Oxford, v. 10, no. 2, p. 87-97, May 1988

30. WATAHA, J. C. Biocompatibility of dental casting alloys: a review. J. Prosthet. Dent., St. Louis, v. 83, no. 2, p. 224-234, Feb. 2000.

\section{Endereço para correspondência}

Luciane Macedo de Menezes

Faculdade de Odontologia da PUCRS

Av. Ipiranga, 6681 - Prédio 06 - Sala 209

CEP: $90.619-900$ - Porto Alegre/RS

E-mail: luciane@portoweb.com.br 